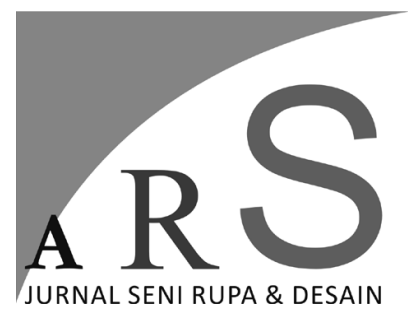

Volume 22 Nomor 1 - April 2019

\section{PESONA KEBAYA ENCIM MODIFIKASI DALAM SENTUHAN MOTIF BATIK MEGA MENDUNG}

\author{
Septina Kurniasri Lestari \\ Program Studi D3 Batik dan Fashion, Jurusan Kriya \\ Fakultas Seni Rupa, Institut Seni Indonesia Yogyakarta \\ E-mail: septinalee@gmail.com
}

\begin{abstract}
ABSTRAK
Berawal dari kecintaan terhadap budaya dalam negeri yaitu batik dan kebaya, maka dalam karya penciptaan ini diambil kebaya encim sebagai sumber ide penciptaannya, sekaligus turut serta memberikan sedikit andil dalam usaha pelestarian dan pengembangannya. Sulam yang merupakan ciri khas dari kebaya encim akan digantikan dengan teknik batik lorodan untuk mengaplikasikan motif Mega Mendung yang menjadi motif hiasan pada kebaya. Metode penciptaan yang digunakan dalam penciptaan karya ini adalah metode pengumpulan data melalui studi pustaka dan observasi langsung, metode analisis data, metode perancangan, dan metode perwujudan yang keseluruhannya menggunakan teknik tradisional batik tulis dengan proses colet dan tutup celup pada pewarnaannya serta proses jahit mesin untuk pengerjaan busananya. Hasil akhir dari penciptaan karya busana berupa kebaya encim modifikasi ini menghasilkan karya yang mempunyai ciri khas warna cerah. Dari penciptaan karya ini diharapkan dapat memberikan kontribusi yang bermanfaat terhadap perkembangan dunia seni kriya terutama tekstil, dan juga dapat menumbuhkan kecintaan masyarakat terhadap kebaya dan batik agar dikenakan dalam berbagai kesempatan.
\end{abstract}

Kata kunci: kebaya encim, batik, mega mendung

\begin{abstract}
Kebaya encim, the traditional fashion item of Betawi women, needs to be preserved and developed. It contains artistic and aesthetic values that might be used as an inspiration source in creating art items as done in this fashion designing process. To embellish it, batik is used to replace embroidery, the characteristic of kebaya encim. Mega mendung motif applied on these tops is created using lorodan technique. The creative process covers: (1) data collection by means of literature review and observation; (2) data analysis; (3) design stage; and (4) application stage. The coloring of this handmade batik is done using colet (painting) and tutup celup (waxing and dying) processes. These techniques result in bright colors. At the end, a sewing machine consummates the whole steps to tailor the cloth. This kebaya encim making process is hoped to contribute to the development of textile craft and persuade Indonesians to love kebaya and batik.
\end{abstract}

Keywords: kebaya encim, batik, mega mendung 


\section{Pendahuluan}

Setiap negara pasti mempunyai kebudayaan, baik dalam bentuk benda maupun tak benda. Batik merupakan salah satu kain tradisional Indonesia yang telah diakui UNESCO sebagai Masterpieces of the Oral and Intangible Heritage of Humanity. Dahulu, penggunaan kain batik selalu dikaitkan erat dengan pemakaian kebaya. Menurut perancang busana Ferry Setiawan yang dipaparkan dalam Tempo," disebutkan bahwa pada era 1940-an, kebaya dipilih Presiden Soekarno sebagai kostum nasional. Saat itu kebaya dianggap busana tradisional perempuan Indonesia dan menjadi lambang emansipasi wanita" (Putra, 2012). Kebaya merupakan busana yang lazim dikenakan oleh perempuan Indonesia terutama perempuan Jawa antara abad ke-15 dan ke-16 Masehi, berupa atasan yang dipadukan dengan kain batik sebagai jarit atau kain bawahan. Pada abad ke19 kebaya tidak hanya dipakai perempuan Jawa saja, akan tetapi juga perempuan peranakan, bahkan kebaya menjadi busana wajib perempuan Belanda yang hijrah ke Indonesia (Pentasari, 2007: 11-15). Kedatangan bangsa asing di Indonesia membawa pengaruh terhadap kebaya yang menjadikannya kaya dan beragam. Salah satunya akulturasi dengan budaya Tiongkok yang menghasilkan kebaya encim. Dalam Kamus Mode Indonesia disebutkan, bahwa kebaya encim merupakan istilah lain dari kebaya China yang baru mulai digunakan sekitar tahun 1970-an, ketika model kebaya ini dipopulerkan kembali dan terus digemari hingga sekarang (Hardisurya, Irma, Mardiana, Ninuk \& Yusuf, 2011: 118). Menurut Henry Hasyim, seorang perancang yang tetap berpakem pada potongan kebaya yang asli berpendapat, bahwa potongan khas kebaya encim tampak di bagian depan yang memanjang dan lancip, sedangkan bagian belakang terkesan pendek" (Bondan, 2015: 40).

Busana peranakan Cina ini merupakan kebaya paling kasual di antara kebaya lainnya, karena potongannya sederhana dengan bahan katun sangat nyaman, bahkan jika digunakan untuk beraktivitas sehari-hari. Sayangnya, di zaman modern seperti ini pemakaian kebaya encim masih diasumsikan sebagai busana formal yang hanya bisa digunakan pada acara-acara tertentu.
Walaupun sangat familiar dan banyak digunakan, ternyata masih banyak masyarakat yang tidak tahu kalau kebaya peranakan ini bernama kebaya encim, karena umumnya mereka hanya mengenal encim sebagai sebuah kebaya saja. Banyak desainer Indonesia yang sudah mengadaptasi dan mengembangkan kebaya encim sesuai dengan perkembangan zaman. Adapun motif hiasan yang dipakai tidak lagi hanya berupa flora dan fauna semata, akan tetapi juga menambahkan ragam hias Betawi yang mengusung kebiasaan dari keseharian masyarakatnya, misalnya motif OndelOndel, Si Pitung, Pengantin Betawi, Teratai, dan Monas (Clara, 2011: 78). Melihat hal ini, maka muncullah sebuah gagasan untuk mengganti teknik bordir pada kebaya encim dengan teknik dan motif batik. Sentuhan batik yang diterapkan untuk menggambar motifnya merupakan hal baru yang selama ini belum pernah dilakukan.

Mega Mendung merupakan motif mega atau awan-awanan yang melambangkan pembawa hujan, pemberi kesuburan, dan kehidupan. Tidak seperti batik yang mempunyai arti filosofis pada motifnya, motif pada kebaya encim hanya menggambarkan keindahan. Oleh karena itu, motif Mega Mendung yang diaplikasikan pada kebaya ini diharapkan membuatnya menjadi lebih bermakna.

\section{Tujuan Penciptaan}

Mewujudkan busana kebaya encim modifikasi dengan motif batik Mega Mendung yang diaplikasaikan menggunakan teknik batik sehingga menjadi motif pada kebaya.

\section{Landasan Teori}

Teori Busana"Busana dalam arti umum adalah bahan tekstil atau bahan lainnya yang sudah dijahit atau tidak dijahit, yang dipakai atau disampirkan untuk menutupi tubuh seseorang. Dalam arti sempit, busana dapat diartikan sebagai bahan tekstil yang disampirkan atau dijahit terlebih dahulu, dan dipakai untuk menutupi tubuh seseorang yang langsung menutup kulit ataupun tidak langsung menutup kulit"(Sari, 2012: 3). Nilai fungsi busana: (1) Aspek Biologis, sebagai pelindung tubuh dari cuaca dingin, panas sinar matahari, debu, dan gangguan binatang, serta melindungi tubuh dari benda-benda lain 
yang membahayakan kulit; (2) Aspek Psikologis, dapat meningkatkan keyakinan dan rasa percaya diri dan bisa memberikan rasa nyaman; (3) Aspek Sosial, Untuk menutupi aurat, menggambarkan adat atau budaya suatu daerah dan media komunikasi nonverbal. Busana yang dikenakan dapat menyampaikan misi atau pesan kepada orang lain yang terpancar dari kepribadian diri pemakainya (Al-Firdaus, 2010: 11).

\section{Teori Desain}

Teori tentang desain ini ditulis berdasarkan pada teori Bruce Archer yang mengemukakan, bahwa desain merupakan salah satu bentuk kebutuhan hidup manusia yang dijabarkan melalui berbagai bidang pengalaman, keahlian, dan pengetahuan selama beradaptasi dengan lingkungan sekitarnya terutama yang berhubungan dengan bentuk, komposisi, arti, nilai dan berbagai tujuan benda buatan manusia (Sachari, Agus \& Sunarya, 2008: 5). Desainer adalah seorang seniman yang mengekspresikan ide dan kreativitasnya ke dalam bentuk rancangan busana. Proses perancangannya memadukan ilmu seni rupa dan ilmu lain yang mendukung untuk mewujudkan rancangannya.

Unsur desain merupakan unsur-unsur yang digunakan untuk mewujudkan desain dan mempunyai elemen-elemen dasar antara lain: (1) Garis, garis merupakan unsur paling tua yang digunakan oleh manusia dalam mengungkapkan perasaan atau emosi; (2) Arah, arah dapat dilihat dan dirasakan keberadaannya misalnya mendatar, tegak lurus, dan miring; (3) Bentuk, bentuk adalah hasil hubungan dari beberapa garis yang mempunyai area atau bidang dua dimensi dan apabila disusun dalam satu ruang akan terjadi bentuk tiga dimensi; (4) Ukuran, ukuran merupakan salah satu unsur yang mempengaruhi desain pakaian ataupun benda lainnya. Dalam suatu desain ukuran harus diperhatikan guna menghasilkan bentuk yang baik dan seimbang; (5) Tekstur, tekstur merupakan keadaan permukaan suatu benda atau kesan yang timbul dari sesuatu yang terlihat pada permukaan benda dan dapat diketahui dari melihat atau meraba benda tersebut; (6) Value (Nada Gelap dan Terang), adanya cahaya membuat permukaan suatu benda terlihat bagian gelap dan terang. Nada gelap dan terang pada suatu permukaan benda tersebut disebut dengan istilah value; dan (7) Warna, salah satu unsur penting dalam seni rupa, merupakan unsur desain yang paling menonjol dan dapat mengungkapkan perasaan atau sifat suatu benda. Tidak hanya itu warna juga berperan dalam segala aspek kehidupan terutama dalam proses penciptaan karya. Berhubungan dengan teori tentang warna, digunakan teori Albert $\mathrm{H}$. Munsel dalam buku yang ditulis Dharsono Kartika (2004: 48-50) yaitu tentang dimensi kualitas warna yang mengarah pada hue, value dan intensity.

\section{Teori Bahan \\ Kain}

Jenis kain yang bisa digunakan untuk batik adalah jenis kain dengan bahan dasar serat alam yang bisa meresap warna. Kain tersebut dapat terbuat dari bahan sutera, katun prima, primisima, polisima, dobi, paris, atau shantung.

\section{Zat Pewarna}

Pewarnaan pada tekstil dapat dibedakan menjadi dua macam menurut sumber diperolehnya zat warna, yaitu pewarna alam dan pewarna sintetis (Wulandari, 2011: 79). Karya ini secara keseluruhan diproses menggunakan zat pewarna sintetis (kimia).

\section{Metode Penciptaan}

Metode penciptaan karya ini mengacu pada pola tiga tahap enam langkah milik Gustami (2007: 329-332), untuk menciptakan karya yang berfungsi praktis teori ini dirasa mudah dan sistematis untuk diikuti. Tahap pertama eksplorasi yang meliputi aktifitas pencarian data referensi dan penggalian sumber ide dengan langkah identifikasi dan perumusan masalah, kemudian dilanjutkan dengan pengolahan dan analisis data, sehingga didapatkan kesimpulan penting tentang konsep dan pemecahan masalah secara teoritis. Kedua, tahap perancangan yaitu penuangan ide dalam bentuk sketsa alternatif untuk selanjutnya dipilih beberapa sketsa terbaik yang nantinya akan dijadikan sebagai acuan, sehingga mempermudah proses perwujudan. Ketiga adalah tahap perwujudan yang meliputi penciptaan karya sesuai dengan pola pada ukuran sebenarnya yang telah dibuat dengan rinci dan detail meliputi material, 
teknik konstruksi, bentuk dan unsur estetik, dan sebagai langkah terakhir dilakukan evaluasi karya. Pada proses penciptaan karya ini mengacu pada beberapa teori yang berhubungan dengan teori penciptaan yang mendukung seperti: teori busana, teori desain, teori warna dan teori bahan. Pengertian-pengertian tentang hal tersebut sangat penting untuk dipahami karena akan sangat berpengaruh, serta dapat membantu dalam proses berkarya selanjutnya.

\section{Kontribusi}

Kebaya tradisional perlu dipertahankan keasliannya demi kelestarian budaya Indonesia, sementara di sisi lain pengembangannya yang mengikuti tren juga harus dilakukan agar eksistensinya sebagai budaya tradisional tetap hidup di tengah masyarakat modern, sehingga kebaya lebih bisa diterima dan tetap berjaya baik sebagai bagian dari pakaian tradisional maupun tampil kasual khas anak muda. Kebaya encim dan batik merupakan salah satu kekayaan budaya Indonesia. Dengan menciptakan sesuatu yang baru dan berbeda dimaksudkan untuk memperagam kebaya encim yang telah ada, sebagai salah satu usaha pelestarian terhadap kekayaan budaya Indonesia tersebut.

\section{Pembahasan}

Karya 1

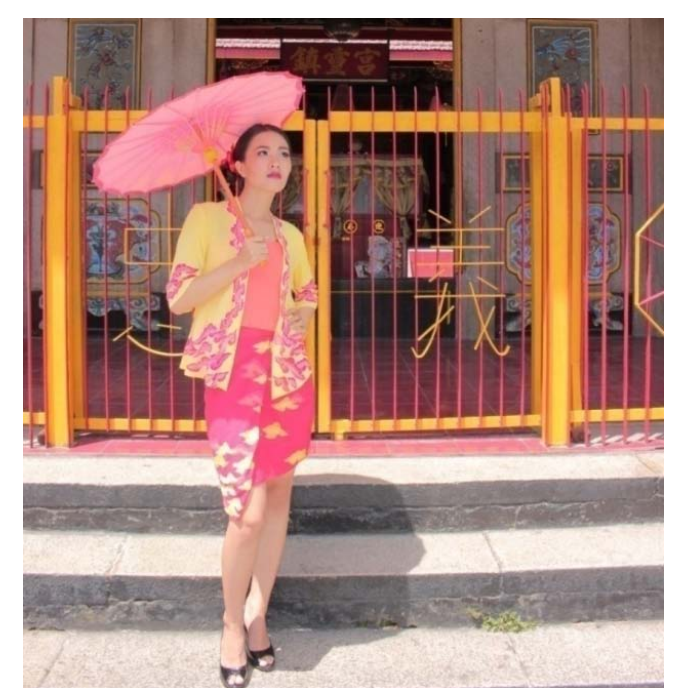

Gambar 1. Karya 1

Judul : Ncim-ncim

Media : Paris, Primissima Gamelan

Teknik : Batik Tulis

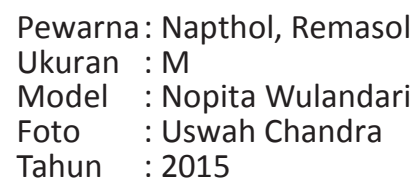

\section{Tinjauan Karya}

Nuansa perayaan tahun baru Cina selalu identik dengan warna-warna panas seperti kuning dan merah. Bagi orang Cina, warna tersebut melambangkan keberuntungan. Karya pertama berjudul Ncim-Ncim, di mana nuansa Cina tersebut dihadirkan. Bermakna encim dalam istilah baru yang merupakan modifikasi dari kebaya encim dengan penambahan kutu baru tetapi tidak mengurangi cita rasa dari encim itu sendiri. Hiasan motifnya masih menghiasi seluruh pinggiran belahan depan dan lengan serta bagian ujung pinggiran bukaan depan berbentuk runcing khas kebaya encim asli. Kebaya encim merupakan hasil akulturasi berbagai budaya dengan budaya Tionghoa. Pengaruhnya sangat terasa pada karya kebaya ini yang menghadirkan warna merah dan kuning bercita rasa Cina. Dipadukan dengan rok pendek berpotongan asimetris memberikan kesan muda yang kasual dan bebas. Motif batik Mega Mendungnya mempunyai warna senada, merah dan kuning dengan gaya pewarnaan kontemporer di luar pakem. Secara keseluruhan karya ini dibuat dengan menonjolkan nuansa Cina dalam bentuk serba baru.

\section{Karya 2}

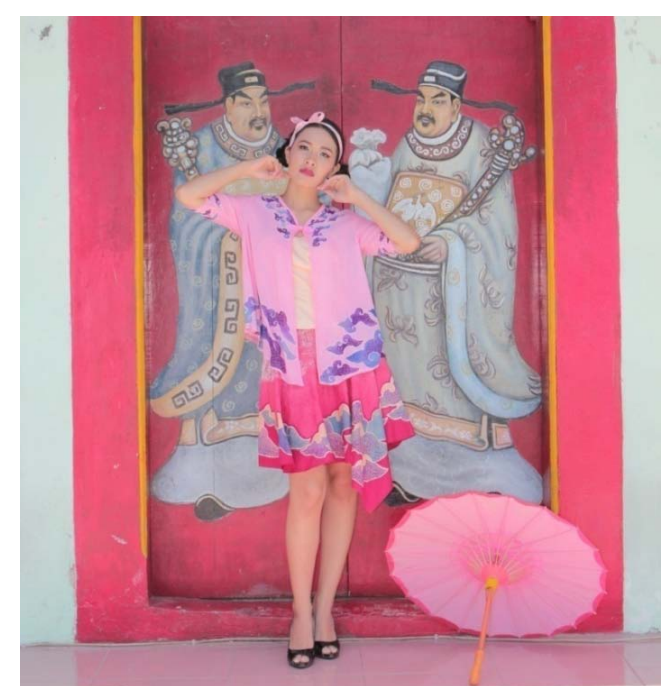

Gambar 2. Karya 2 


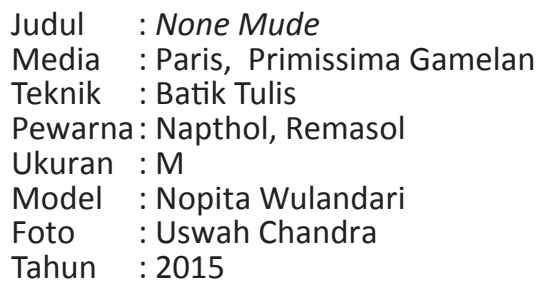

\section{Tinjauan Karya}

Karya kedua berjudul None Mude, merupakan penyebutan dalam logat Betawi dari kata nona muda. Seperti arti judulnya, kebaya ini menggambarkan sisi feminim dari seorang gadis muda. Warna merah muda pada kebaya sangat identik sebagai warna gadis dan memberikan kesan fresh and young. Bentuk kebayanya sudah sangat terlihat termodifikasi, penggunaan bisban sebagai penyelesaian akhir dengan warna senada membuat kebaya ini semakin terlihat berbeda dan cantik, serta tambahan kancing cina sebagai penutup bukaan depan menambah kesan oriental yang mendalam. Walaupun demikian, dalam karya kedua ini, ciri khas kebaya encim yang mempunyai ujung depan runcing serta peletakan motif pada bagian tepian juga masih dipertahankan. Rok lingkar asimetris sebagai bawahan dari kebaya ini mempunyai warna yang senada, merah jambu dengan latar kain yang sedikit abstrak hasil dari teknik remukan parafin basah. Motif Mega Mendung yang diaplikasikan diberikan isen-isen berupa ukel-ukel dengan pewarnaan kontemporer yang jauh berbeda dengan motif Mega Mendung pada umumnya.

\section{Karya 3}

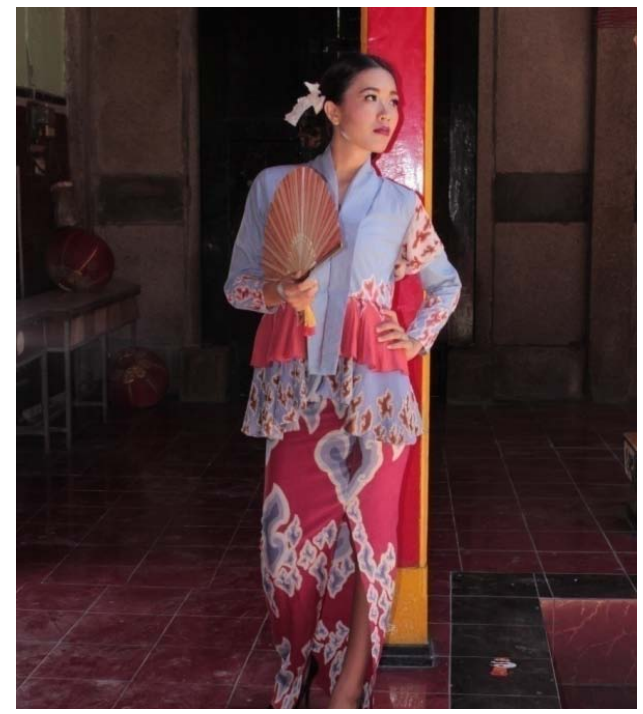

Gambar 3. Karya 3

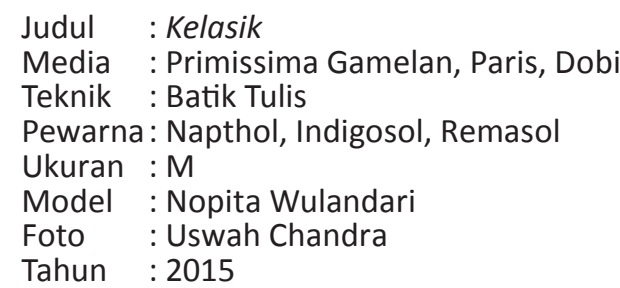

Tinjauan Karya

Karya ketiga ini menampilkan siluet klasik kebaya yang sangat kental. Hal ini yang melatarbelakangi penamaan Kelasik sebagai judulnya. Kelasik merupakan gambaran tentang masa lampau yang ditampilkan dalam siluet busana ini namun tetap bertahan di era modern saat ini. Warna abu-abu dipadankan dengan merah maroon membuat kebaya ini terlihat lebih anggun. Tampilannya secara keseluruhan menegaskan bentuk busana formal, berupa kebaya lengan panjang dipadukan rok span panjang dengan belahan depan yang tinggi. Modifikasi pada leher menjadi kerah setali ala kebaya Jawa menambah keklasikan dari kebaya ini. Potongan pada pinggang yang menghasilkan bentuk peplum bertingkat menjadikan kebaya ini terlihat jauh lebih modern. Aksen tambahan pada satu bagian lengan berupa lengan lonceng pendek membuat kebaya ini menjadi asimetris. Kebaya ini juga dihiasi dengan manik-manik sebagai pemanis sehingga cocok dikenakan sebagai busana pesta. Motif Mega Mendungnya mempunyai gaya pewarnaan yang juga sangat klasik, yaitu gradasi warna bertingkat dari muda ke tua.

\section{Kesimpulan}

Menciptakan sebuah karya baru merupakan tantangan tersendiri bagi seseorang yang masih sangat awam dalam dunia penciptaan. Namun melalui penciptaan ini banyak ilmu, pengalaman, dan pembelajaran yang diperoleh selama prosesnya. Karya bertajuk "Kebaya Encim Modifikasi dalam Sentuhan Motif Batik Mega Mendung" ini merupakan hasil dari serangkaian proses berkesenian yang menggambungkan teknik tradisional batik dengan modernitas kebaya di bidang fashion. Potongan yang simpel dengan sentuhan motif ringan pada kebaya encim modifikasi ini diharapkan membuat banyak perempuan masa kini tidak segan lagi untuk 
memakai kebaya di berbagai kesempatan formal dan informal.

Kesulitan dan tantangan pasti dialami pada proses penciptaan suatu karya seni, khususnya pada penciptaan ini sering ditemui kegagalan selama proses pewarnaan sehingga harus diulang berkali-kali untuk mendapatkan hasil yang diinginkan. Warna yang telah dikonsep sebelumnya seringkali gagal diwujudkan karena satu dan lain hal, sehingga terpaksa diberikan warna lain. Proses pelorodan juga memengaruhi warna kain yang dihasilkan, dimana warna pada kain bisa saja luntur hingga 50 persen.

Cuaca yang kurang mendukung dan kualitas bahan pewarna yang dijual dipasaran juga turut mempengaruhi hasil dari tahap pewarnaan karya-karya ini. Namun dari semua kendala yang dihadapi justru tercipta warna yang tidak terduga pada hasil akhirnya yang juga tidak kalah bagus dari warna yang direncanakan sebelumnya. Setelah melalui penciptaan karya ini bisa dirasakan bagaimana sulitnya menciptakan karya dengan teknik batik tradisional yang membutuhkan ketelatenan, kesabaran, dan ketelitian serta keikhlasan hati agar terwujud hasil akhir yang sempurna.

Inovasi yang diterapkan pada karya ini merupakan suatu hal yang sangat baru dan yang belum pernah dilakukan sebelumnya sehingga masih banyak kekurangan yang dijumpai pada karya ini. Oleh sebab itu, kritik dan saran bagi penulis sangat diharapkan demi terciptanya karya yang lebih baik pada proses berkarya selanjutnya.

\section{Kepustakaan}

Al-Firdaus, I. (2010). Inspirasi-inspirasi

Menakjubkan Ragam Kreasi Busana,.

Yogyakarta: Diva Press,.
Bondan, A. (2015). "Kebaya Busana Legenda Indonesia.” Kompas. Surabaya.

Clara, R. (2011). "Budaya Betawi di Lembaran Katun dan Sutra." Kriya Indonesia Craft, No.27.

Gustami, S. (2007). Butir-Butir Mutiara Estetika Timur: Ide Dasar Penciptaan Seni Kriya Indonesia,. Yogyakarta: Prasista.

Hardisurya, Irma, Mardiana, Ninuk \& Yusuf, H. (2011). Kamus Mode Indonesia. Jakarta: PT. Gramedia Pustaka Utama.

Kartika, D. S. (2004). Seni Rupa Modern. Bandung: Rekayasa Sains.

Pentasari, R. (2007). Chic in Kebaya: Catatan Inspriratif untuk Tampil Anggun Berkebaya. Jakarta: Esensi.

Putra, A. H. (2012). Asal-usul Kebaya, dari Tradisional ke Pentas Pesta.

Sachari, Agus \& Sunarya, Y. Y. (2008). Sejarah dan Perkembangan Desain dan Dunia Kesenirupaan di Indonesia. Bandung: Institut Teknologi Bandung.

Sari, P. S. (2012). Teknik Praktis Mendesain Baju Sendiri. Jakarta: Dunia Kreasi.

Wulandari, A. (2011). Batik Nusantara: Makna Filosofis, Cara Pembuatan, dan Industri Batik. Yogyakarta: CV Andi.

\section{Webtografi}

Putra, Aditya Herlambang. (2012), Asalusul Kebaya, dari Tradisional ke Pentas Pesta, http://www.tempo.co/read/ news/2012/04/20/110398376/Asal-usulKebaya-dari-Tradisional-ke-Pentas-Pesta, diakses 19 Pebruari 2015, pukul 10.15 WIB. 